\title{
To Improve Presentation Skills of the Engineering students through a Vis-à-vis Evaluation Approach - A Pedagogical Experiment.
}

\author{
Jayanti Shinge ${ }^{1}$, Sanjay Kotabagi ${ }^{2}$ \\ ${ }^{1}$ Faculty, Department of Humanities and Social Sciences, KLE Technological University, Hubli, Karnataka. \\ ${ }^{2}$ Head of the Department of Humanities and Social Sciences, KLE Technological University, Hubli, Karnataka. \\ 1jayanti_s@kletech.ac.in \\ ${ }^{2}$ sanjay_kotabagi@kletech.ac.in
}

\begin{abstract}
Today's employee has to prepare himself for all possible ways to interact with people, be it in person, video conference, tele-conference, Skype, presentation, etc. It becomes inevitable for today's aspiring Engineers to jump in for key posts in the corporate world to master their presentation skills. The need for our students to excel in presentation skill prompted us to go for a small experiment with a sample size of 10 freshman students.
\end{abstract}

After we had a detailed discussion with the stakeholders (HODs, Placement officer, Deans and sample group of students) on campus before revisiting the Professional Communication course content which is delivered to the freshman students; we learnt that our students required an immediate intervention in improving their presentation skills. This prompted us to research and go in for a pedagogical experiment.

This paper talks about the approach that was coined in detail after years of teaching Professional Communication Course for freshman students of Engineering at KLE Technological University, Hubli.

We called it The Vis-a-Vis Approach as Vis-a-Vis basically is a French word which means "face to face". This approach was coined keeping in mind as to help the students know themselves and their shortcomings better through a thorough discussion which happens one on one between the faculty and the student away from the class environment after the assessments. The discussion actually begins by getting to know the students and his life and his parents back home and his hobbies. This personal touch opened the gates to make student realize their shortcomings as far as the presentations were concerned more meaningfully.

\section{Keywords:}

Vis - a - Vis Approach, Baseline, Mid-term, Final Evaluation, Presentation Skills, Rubric, freshman, Reading Skills.

\section{Introduction:}

The first thing that comes to our minds when we hear this term "an engineering student" is a stereotypical, overworked student whose work consists of nothing but endless calculations. Many of us would not attribute writing and public speaking to the average engineer's career at all. When it comes to all this, engineers leave that stuff to the humanities students.

Although the "overworked student" stereotype is still accurate, what most people don't realize is just how prominent and vital communication skills have become in the field of engineering. We can define "communication skills," as anything that has to do with communication. This broad definition includes Listening skills, Speaking Skills, Reading Skills, and Writing Skills (LSRW).

The role of engineers has been on a roller coaster ride from the past few decades making a paradigm shift into redefining the myriads of skill sets to be imbibed by the freshers coming out from the different engineering colleges of India. Today's engineering student has to have skills like problem solving, project management, learn to learn, relearn and unlearn, analytical and creative skills, ethical and professional behaviour, technical skills, design oriented, positive attitude and to present these skills optimally they require good communication skills especially effective presentation skills. 
So why should engineers want to hone their communication skills? One big reason that should catch student's attention is that it is a valuable career enhancer. Employers want engineers with strong communication skills. They assume most people who graduate with an engineering degree have the technical expertise to do their jobs; what employers are looking for in a candidate is the ability to communicate their findings with others in a productive, efficient manner. In today's world, it is essential for an engineer to possess strong communication skills; it is the biggest determiner of success in the modern engineer's professional career. ${ }^{1}$

A recent research found that $78 \%$ of a sample of practicing engineering graduates stated that they were required to give oral presentations as part of their work, and quite often this was on a regular basis. Group projects and presentations encourage and enhance the interpersonal skills of the student members and should be emphasized early in the education curricula. This should be considered in particular as teamwork is recognized as a core skill in industry, and communication with team members needs to be effective. Presentation as a group task enhances interpersonal skills. Nowadays business organizations pay attention on presentation skills of a professional. ${ }^{2}$

\section{Need analysis:}

The journey started when we started talking to stakeholders from KLE Tech Campus capturing their insights on enquiring how we can improve the communication skills of the students beyond what we have been doing as a part of the course Professional Communication delivered for Freshman Engineering students.

Stakeholders like the Hods, Deans, Placement Officer, few recruiters, passed out students, final year students were approached for the discussion. The questions asked to these stakeholders after briefing the background details of the efforts put in by the faculty of Dept of Humanities and Social Sciences towards improving the communication skills of the students were,

1. What is the performance of the students as far as communication skills are concerned?

2. Do you assess communication skills of the students during your project reviews?

3. How do you assess them?

4. How do you think they perform?

5. Which is the most affected element when it comes to LSRW?

6. How do you think we can improve this element?

7. Any suggestions for the faculty of Professional Communication.

We learnt from the thorough discussion with the stakeholders that,
1. Students cannot frame grammatically understandable statements.

2. They lack presentation skills.

3. They don't know how to speak in public.

4. Lack of knowledge on body language.

5. Though they are technically sound they don't know how to express their ideas in well constructed statements.

6. They lack confidence due to lack of communication skills.

7. Students encountered problems when delivering technical oral presentations especially in terms of content, delivery and language.

We spoke to few passed out students and few final year students. The questions listed below were asked to them for their inputs.

1. How would you like to rate your communication skills on the scale of 10 ?

2. How would you like to scale you on the following on the scale of 10 ?

1. Listening Skills

2. Speaking Skills

3. Reading Skills

4. Writing Skills

5. Presentation Skills

3. What troubles you most during your project presentations?

4. What stands alarming when it comes to your experiences with attempted interviews so far?

5. What do you think presentation skills stand for?

6. How long do you plan and prepare before you present your ideas regarding your project or work before the audience?

7. Do you write a script before facing the audience?

8. Do you record your speech before its delivery?

The inferences drawn out from the responses that we got from the students are,

1. Most of the students rated their communication skills in between 5 and 6 .

2. Students underrated themselves on Speaking Skills, Writing Skills and Presentation Skills.

3. Lack of confidence when speaking about the work they have done or have been doing is the most challenging part for them.

4. They accepted that they make mistakes while speaking unknowingly.

5. According to them presentation skills is to present what one knows. 
6. Expressing effectively, fluently without making grammatical errors was and is the most challenging part of placement interviews.

7. $10 \%$ of the students agreed that to plan and prepare beforehand is a better option for any sort of presentation.

8. According to them planning and preparing does not consists of writing script or recording their speech before presentation. They believe in last moment preparations as according to them everything that is read recently remains loud, clear and vivid in their minds.

9. $20 \%$ of the respondents said they would do almost anything to avoid giving a presentation including being sick or asking close friends to fill in for them.

After we got these inferences we went in for a brainstorm session as to decide how to tackle the issues. After brainstorm session we unanimously decided to work on improving the presentation skills of the students as it addressed most of the student's problems.

Thus, this actually laid the need analysis of our study.

\section{Research Phase:}

Before we could decide on how to hone the presentation skills of the students we studied weeks together to find out the answer to some of the bubbling questions like,

1. What exactly are Presentation Skills?

2. What method/ approach/ rubric can be designed which answered all our issues?

3. How to do the experiment?

4. What will be the sample?

The research followed by this led to the proper understanding of what constitutes communication skills and the formulation of Vis-à-vis Evaluation Approach - A Pedagogical Experiment to assess engineering students to help them hone their presentation skills.

\section{What are presentation skills?}

Presentation skills are the skills you need in delivering effective and engaging presentations to a variety of audiences. These skills cover a variety of areas such as the structure of your presentation, the design of your slides, the tone of your voice and the body language you convey. ${ }^{3}$

The Vis-à-Vis Evaluation Approach is a unique approach which not only gave an opportunity for the faculty to assess the students on the rubrics designed but also gave the students to self-evaluate on the set rubric. The rubric had been designed on the different parameters keeping in mind the Presentation skills after a thorough brain storm session. The presentation was scheduled at three levels, Base line Evaluation followed by Mid-term Evaluation and End term Evaluation. The Vis-à-Vis Evaluation was done twice firstly after base line Evaluation and secondly after Midterm Evaluation. Soon after the base line evaluation the faculty gave detailed inputs on the required improvements and after mid-term evaluation the faculty further counselled the student with the parameters which students still required fine tuning.

The approach helped the students to realize and work on their shortcomings. The Vis-a-Vis session not only motivated the students but also educated them on the importance of proper presentation skills. It also imbibed in them the read skills. This approach not only improved the scores of the students and boosted their confidence level but it also redefined the role of the faculty from the sage on the stage to the guide by side.

The presentation was divided into three phase,
1. Baseline Evaluation
2. Mid Term Evaluation
3. Final Term Evaluation

Ten students from first year were randomly picked up for the experiment.

\section{Baseline Presentation Evaluation}

The sample students were asked to read the novel "The Monk who sold his Ferrari" in a week's time. And they were asked to present themselves on the topic "What are life lessons you have learnt from the novel "The Monk who sold his Ferrari" by Robin Sharma. The students were not given any instructions as to how to prepare for the presentation. A detailed rubric for assessment was prepared through thorough discussions amongst the faculty.

The rubric was designed in the following fashion. The major parameters were Body language, Delivery, Content which further got segmented to the following.

\section{Body Language (20 marks)}

1. Eye contact (5)

A student had to maintain eye contact with all the ones seated in front of him as audience. The audience was made to sit in a scattered fashion.

2. Hand movement (5)

Right hand movements were on check. Excessive hand movements during presentation showed nervousness and were not considered positive.

3. Posture and Body movement (5)

Posture had to be erect and confident. The right amount of body movements were on check.

4. Facial Expressions (5)

The students had to maintain congruency in the speech and the facial expressions they use. 


\section{Delivery (10 marks)}

1. Grammar/ Vocabulary (3 marks) Students' presentation had to be grammatically right. They had to speak right statements. The usage of vocabulary was monitored.

2. Accent/ Pronunciation (2 marks)

How clearly students could speak was accounted under accent. The pronunciation was also checked thoroughly.

3. Voice Modulation (3 marks)

Most of the students were monotonous. How well students use voice modulation was checked.

4. Rate of Speech / Fluency (2 marks)

How fast students complete a statement was checked without using long pauses and fillers.

\section{Content (20 marks)}

\section{Opening (5)}

The opening message of the students was checked. They had to make it unique and attract the crowd by their strong opening message.

\section{Message (10)}

The message or the body of their presentation had to be rich in information in the form of statistics, anecdotes, and quotes. A thorough study on the topic should be seen in the content they delivered.

3. Closure (5)

The closure had to be impactful.4

The presentations given by the students were recorded in the class. The audience was asked to sit in the scattered fashion.

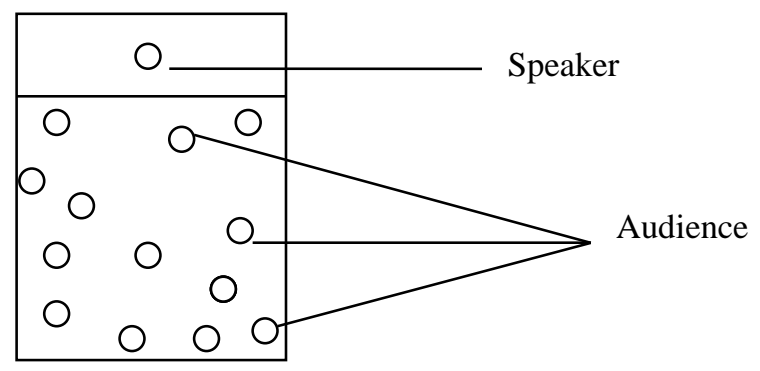

(Fig. 1- Scattered Audience in classroom)
The presentations were recorded. Once the recording was done, the videos were given to the students respectively with the rubrics for self assessment. Post self assessment a day was finalized for the Vis-a-Vis Evaluation, where students were counselled by playing the video all over again in the presence of the faculty and respective student. This approach gave the student get detailed explanation and inputs on their performance keeping the rubrics as base document.

The scores scored by students were not up to the satisfactory level. The students were asked to work on the short comings thoroughly.

The same exercise was repeated twice. For the midterm evaluation the novel students were asked to read was "The Alchemist by Paulo Coelho. This time students were already prepared on the inputs given by the faculty during Baseline presentation. This time students wrote their script beforehand and got it corrected by the faculty. The most important thing they did this time was recording their presentation $\mathrm{n}$ number of times back home before going for class presentations. The videos were again recorded and then the Vis- a- Vis evaluation happened. This time students were more relaxed as the rapport with the faculty was built and they were discussed about their problems openly. The scores were better than the last time.

For the Final Evaluation students were made to watch the movie, "How to Train your Dragon" a 2010 American Computer Animated action fantasy film based on the novel by the same name by British Author Cressida Cowell. The last presentation students presented their learning in the form of presentation. There was a lot of improvement seen in the presentation skills of the students with Vis-a-Vis evaluation approach.

The time was monitored for all the three sessions. First time for Base line Evaluation students were not informed about how to maintain time or for how long they were supposed to engage the audience. The instructions were given for the rest of the two evaluations.

Three flags of colour Green, Orange and Red each were used to denote the time. The ideal time students were asked to speak was ten minutes.

1. Green Flag indicated the student has successfully reached ten minutes.

2. Orange Flag indicated the student spoke half the time or less than that.

3. Red Flag indicated the students spoke more than half the time but less than full time. 


\section{Inputs given during Vis- a- Vis Evaluation post Baseline evaluation and Mid Term evaluation.}

\begin{tabular}{|c|c|}
\hline $\begin{array}{l}\text { Parameters on } \\
\text { Presentation } \\
\text { Skills }\end{array}$ & Inputs Given \\
\hline \multicolumn{2}{|r|}{ A. Body Language } \\
\hline Eye Contact & $\begin{array}{l}\text { 1. To maintain constant eye contact } \\
\text { with all the sections of the } \\
\text { audience. } \\
\text { 2. No proper eye contact shows } \\
\text { student is not confident. } \\
\text { 3. Eye contact does not mean } \\
\text { staring. } \\
\text { 4. Avoiding the audience and } \\
\text { looking at the walls, ceiling and } \\
\text { floor is not advisable. }\end{array}$ \\
\hline $\begin{array}{l}\text { Hand } \\
\text { Movements }\end{array}$ & $\begin{array}{l}\text { 1. Hand gestures should be } \\
\text { congruent with the speech. } \\
\text { 2. No meddling with the fingers and } \\
\text { breaking the knuckles. } \\
\text { 3. Hand should not either be folded } \\
\text { in the front or back. } \\
\text { 4. For boys no hands in the pocket } \\
\text { 5. Excess hand movement also } \\
\text { shows anxiety. }\end{array}$ \\
\hline $\begin{array}{l}\text { Posture and } \\
\text { Body } \\
\text { Movement }\end{array}$ & $\begin{array}{l}\text { 1. One has to be upright and carry } \\
\text { their attire appropriately. } \\
\text { 2. No front and back movements or } \\
\text { side movements unnecessarily. } \\
\text { 3. Continuous and rampant } \\
\text { movements on the dais are not } \\
\text { welcomed as it shows being } \\
\text { nervous. } \\
\text { 4. Not to be rooted at one place. }\end{array}$ \\
\hline $\begin{array}{l}\text { Facial } \\
\text { expression }\end{array}$ & $\begin{array}{l}\text { 1. Facial expressions should be } \\
\text { congruent with the content. } \\
\text { 2. Should not touch the face or head } \\
\text { while delivery, especially when } \\
\text { they tend to forget something in } \\
\text { between the delivery. }\end{array}$ \\
\hline & B. Delivery \\
\hline $\begin{array}{l}\text { Grammar/ } \\
\text { Vocabulary }\end{array}$ & $\begin{array}{l}\text { 1. Using grammatically right } \\
\text { statements. } \\
\text { 2. Using appropriate vocabulary } \\
\text { according to the content. } \\
\text { 3. Language should be simple and } \\
\text { understandable. } \\
\text { 4. Sentences should not be directly } \\
\text { translated from Vernacular to } \\
\text { English. }\end{array}$ \\
\hline
\end{tabular}

\begin{tabular}{|c|c|}
\hline $\begin{array}{l}\text { Accent / } \\
\text { Pronunciation }\end{array}$ & $\begin{array}{l}\text { 1. Should have neutral accent. } \\
\text { 2. No influence of the vernacular } \\
\text { language should be seen in the } \\
\text { pronunciation of the words. }\end{array}$ \\
\hline $\begin{array}{l}\text { Voice } \\
\text { Modulation }\end{array}$ & $\begin{array}{l}\text { 1. The speech should not be } \\
\text { monotonous. } \\
\text { 2. Stress and intonation and pause } \\
\text { pattern should be seen. } \\
\text { 3. The voice should be audible and } \\
\text { clear. } \\
\text { 4. The intonation should not sound } \\
\text { like their vernacular language. }\end{array}$ \\
\hline $\begin{array}{l}\text { Rate of } \\
\text { Speech }\end{array}$ & $\begin{array}{l}\text { 1. It should not be too fast or too } \\
\text { slow. } \\
\text { 2. The delivery should not seem to } \\
\text { be an answer to a question but a } \\
\text { natural speech. } \\
\text { 3. No broken sentences. } \\
\text { 4. No usage of long pauses or voice } \\
\text { fillers like mmm, aaa, hmmm. }\end{array}$ \\
\hline & C. Content \\
\hline Opening & $\begin{array}{l}\text { 1. The opening has to be very } \\
\text { attractive and attention grabbing. } \\
\text { 2. It can start with a quote or } \\
\text { anecdote. } \\
\text { 3. It should set the mindset of the } \\
\text { audience of what is coming in the } \\
\text { rest of the presentation. } \\
\text { 4. It should introduce the students } \\
\text { with the background information } \\
\text { on the topic. }\end{array}$ \\
\hline Message & $\begin{array}{l}\text { 1. The message has to be very rich } \\
\text { with information, fact and figures } \\
\text { on the topic. } \\
\text { 2. The students can use anecdotes } \\
\text { to make the presentation more } \\
\text { effective. } \\
\text { 3. In depth information on the topic } \\
\text { has to be imparted. }\end{array}$ \\
\hline Closure & $\begin{array}{l}\text { 1. Should include their perspective } \\
\text { or views on the topic. } \\
\text { 2. It can also end with quotes. }\end{array}$ \\
\hline $\begin{array}{l}\text { Common } \\
\text { Inputs }\end{array}$ & $\begin{array}{l}\text { 1. There has to be smooth transition } \\
\text { from opening message to the } \\
\text { body of the presentation followed } \\
\text { by the closure. } \\
\text { 2. Students can interact with the } \\
\text { audience in the form asking them } \\
\text { question depending on the } \\
\text { demand of the topic. } \\
\text { 3. Student has to record his voice as } \\
\text { a part of homework before }\end{array}$ \\
\hline
\end{tabular}




\begin{tabular}{|l|l|}
\hline $\begin{array}{l}\text { presentation in the class so that } \\
\text { he/she can work on his/her } \\
\text { pronunciation. Recording will } \\
\text { also help maintain the time } \\
\text { allotted for presentation. }\end{array}$ \\
4. $\begin{array}{l}\text { Student has to write the script } \\
\text { and get it corrected well in } \\
\text { advance. }\end{array}$ \\
5. $\begin{array}{l}\text { Student has to rehearse standing } \\
\text { in front of the mirror so that he } \\
\text { can check his body language for } \\
\text { himself/herself. } \\
\text { Dress code has to be formal or } \\
\text { according to the culture of the } \\
\text { company one is working for. }\end{array}$ \\
\hline
\end{tabular}

\section{The Stacked Cylinder Representation of Data:}

The Assessment was conducted on 50 marks. The representation here shows the scores of each student on 100. The tool Microsoft Excel was used for the analysis.

On $\mathrm{X}$ axis we have the marks of the students scored for all the three evaluations that is Base Line, Mid Term and Final term respectively and $\mathrm{Y}$ axis we have the ten sample students picked up for the experiment.

The blue color speaks about the scores of Baseline evaluation. The red color speaks about the scores of the Midterm evaluation.The green color speaks about the scores of the Final Term evaluation.

\section{Body language}

I. Eye Contact

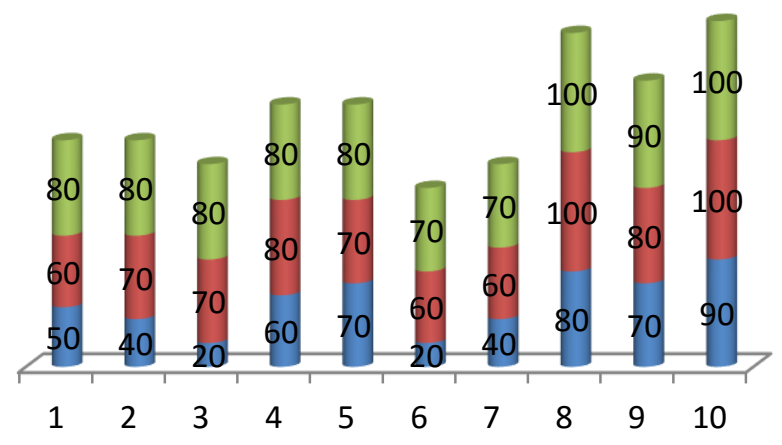

(Fig. 2- Comparison BT, MT, FT- Eye Contact)

\section{Hand Movements}

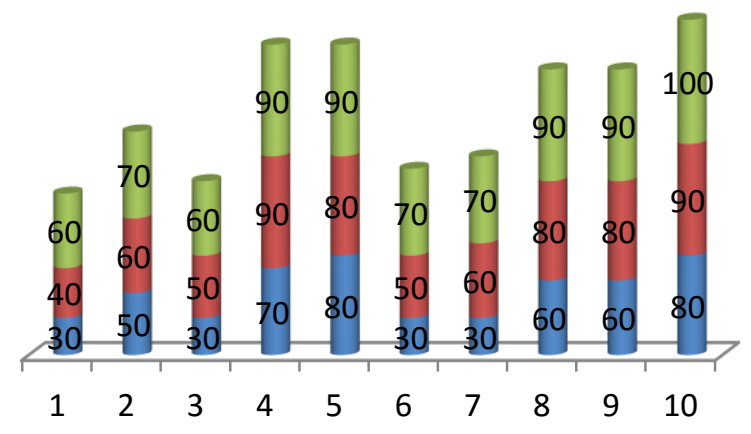

(Fig. 3- Comparison BL, MT, FT- Hand Movements)

\section{Posture and Body Movements}

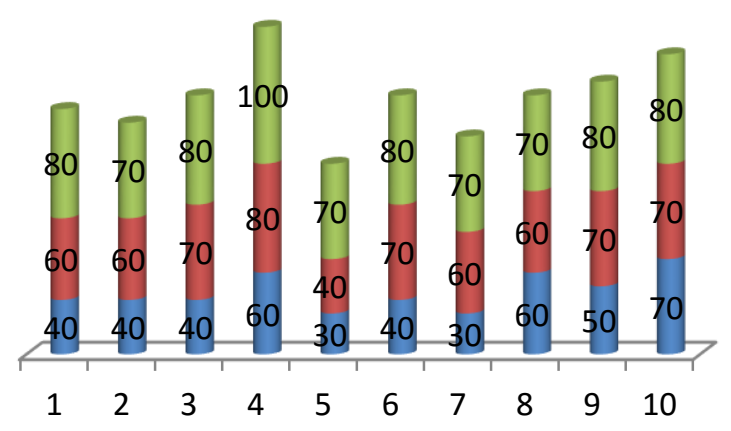

(Fig. 4- Comparison BT, MT, FT- Posture and Body Movements)

\section{Facial Expressions}

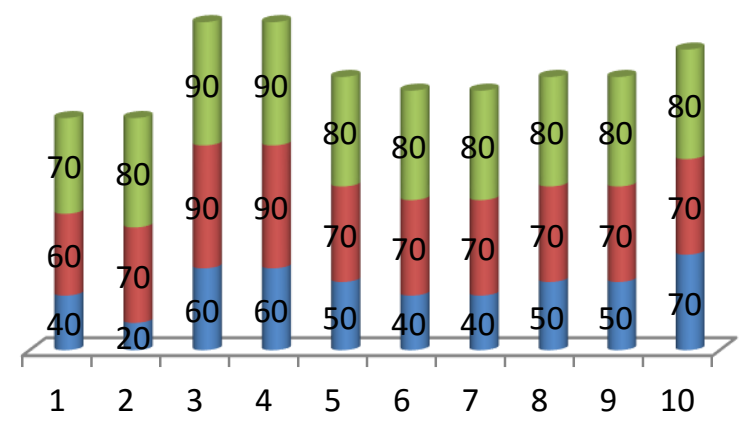

(Fig. 5- Comparison BT, MT, FT- Facial Expressions) 


\section{Delivery}

\section{Grammar/ Vocabulary}

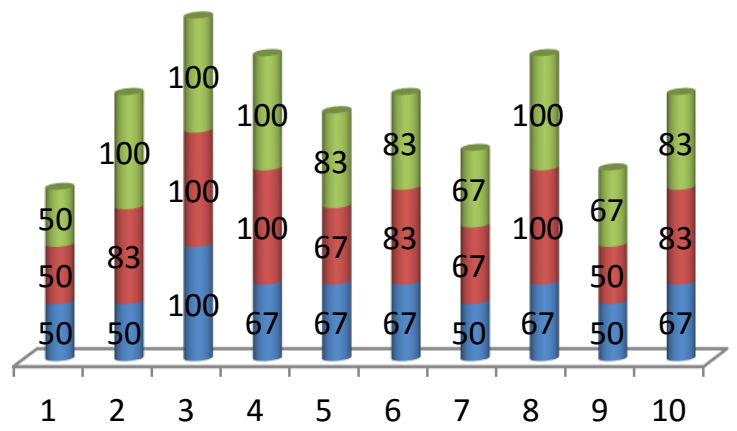

(Fig. 6- Comparison BT, MT, FT- Grammar and Vocabulary)

II. Accent/ pronunciation

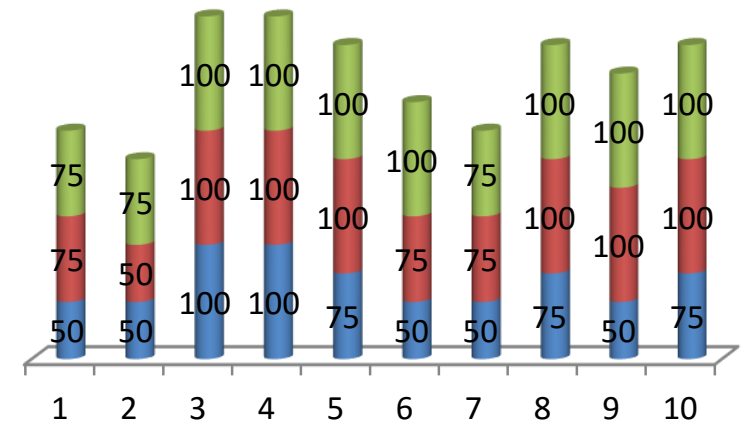

(Fig. 7- Comparison Bt, MT, FT- Accent / pronunciation)

III. Voice Modulation

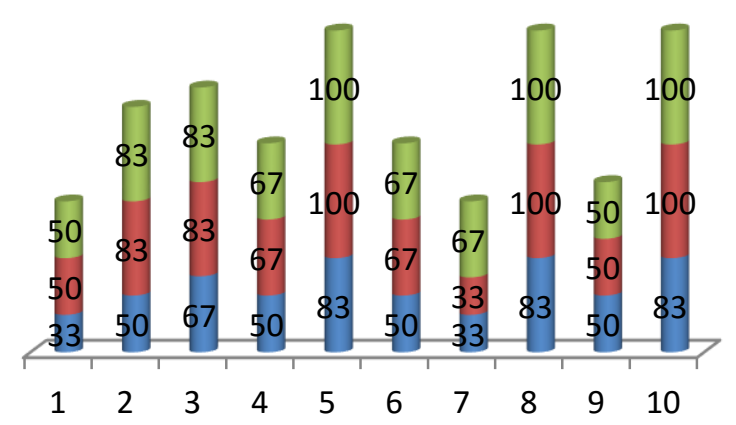

(Fig. 8-Comparison BT, MT, FT- Voice Modulation)
IV. Rate of Speech

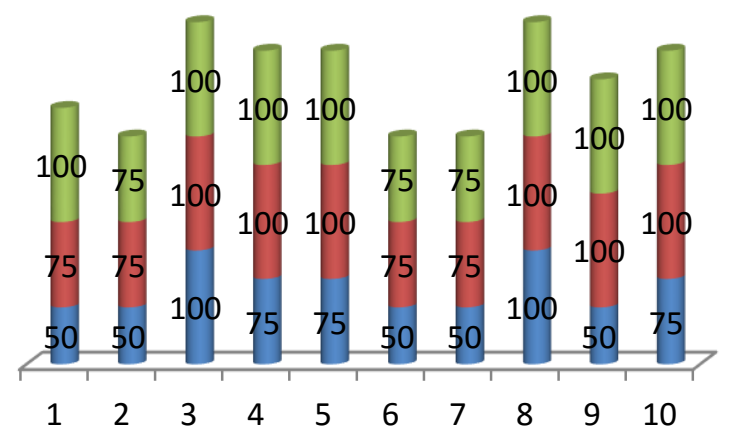

(Fig. 9- Comparison BT, MT, FT- Rate of Speech)

\section{Content}

I. Opening

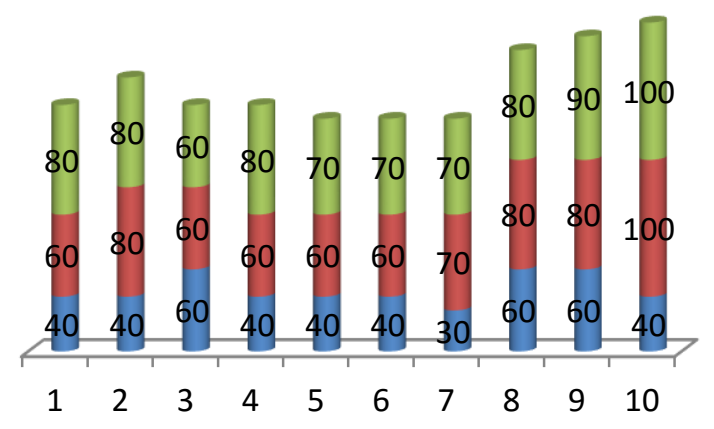

(Fig. 10- Comparison BT, MT, FT- Opening)

II. Message

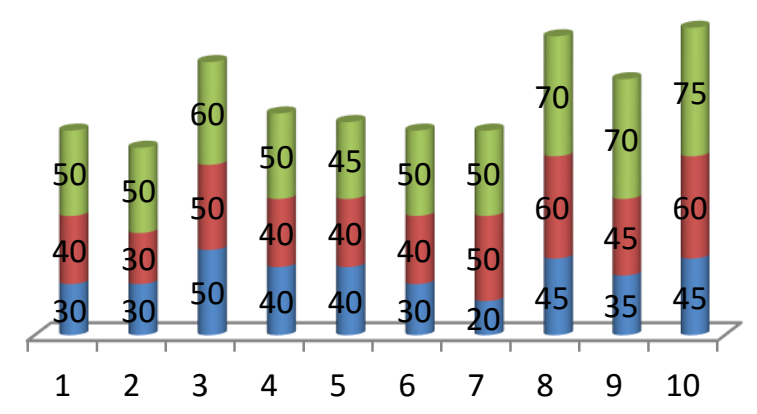

(Fig. 11- Comparison BT, MT, FT- Message)

III. Closure 


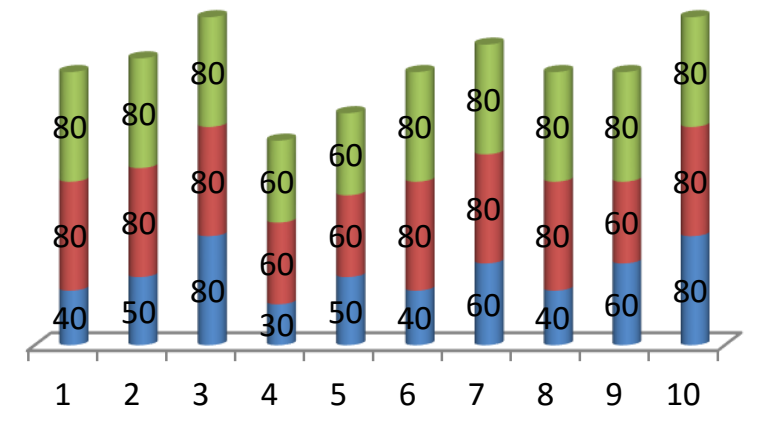

(Fig. 12- Comparison BT, MT, FT- Closure)

\section{Pre Training and Post Training Comparison:}

\section{The Stacked Cylinder Representation of Data:}

The Assessment was conducted on 50 marks. The representation here shows the scores of each student on 100. The tool Microsoft Excel was used for the analysis.

On $\mathrm{X}$ axis we have the comparison of the students scores Pre Training and Post Training and $\mathrm{Y}$ axis we have the ten sample students picked up for the experiment.

The Blue colour speaks about the scores of the Pre Training scores. The Green colour speaks about the scores of the Post Training Evaluation.

\section{Body Language}

1. Eye Contact

- Post Training Status $\quad$ Pre Training Status

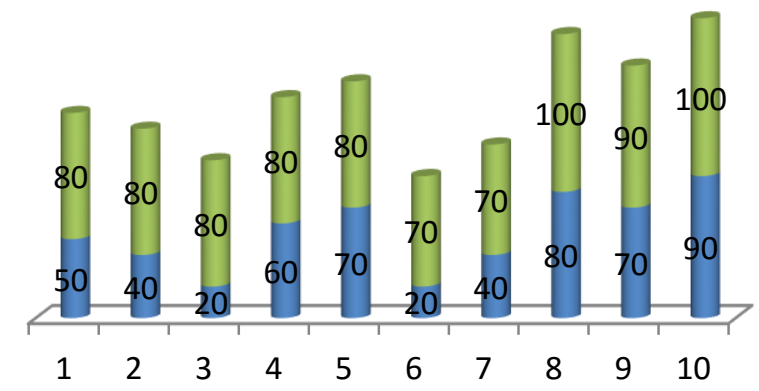

(Fig. 13- Eye contact - Comparison Pre and Post Training)

\section{Hand Movements}

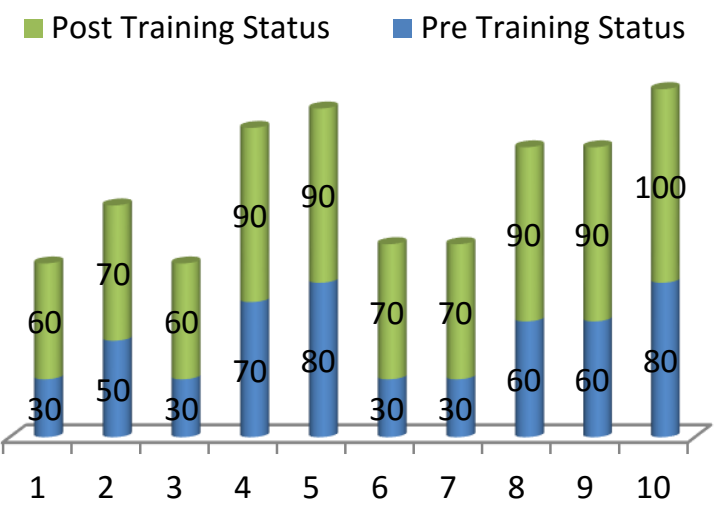

(Fig. 14- Hand movements - Comparison Pre and Post Training)

3. Posture and Body Movements

Post Training Status $\square$ Pre Training Status

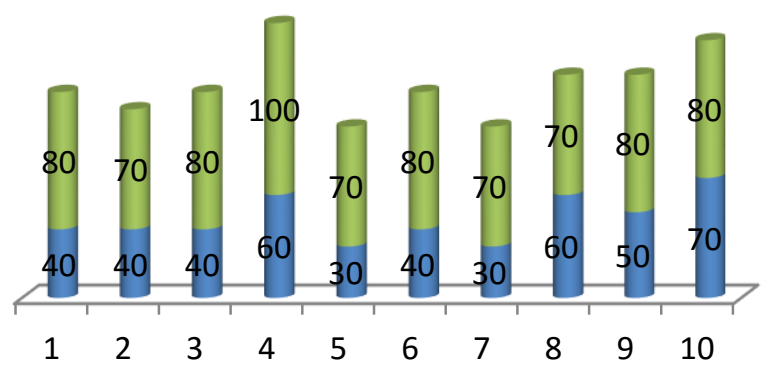

(Fig. 15- Posture and Body Movements - Comparison Pre and Post Training)

\section{Facial Expressions}

Post Training Status Pre Training Status

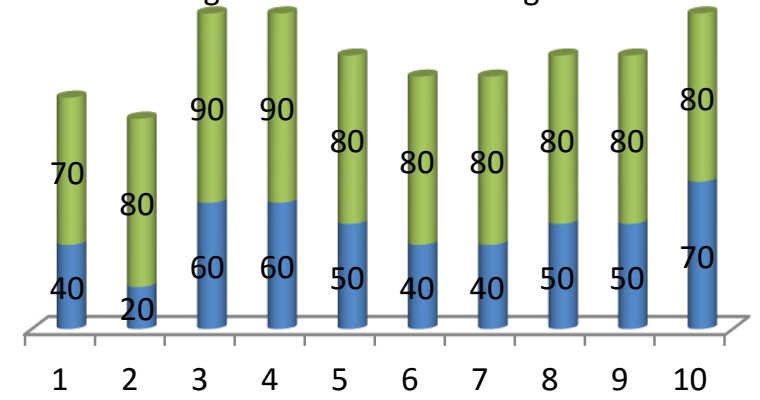

(Fig. 16- Facial Expressions - Comparison Pre and Post Training) 


\section{Delivery}

I. Grammar and Vocabulary

Post Training Status $\quad$ Pre Training Status

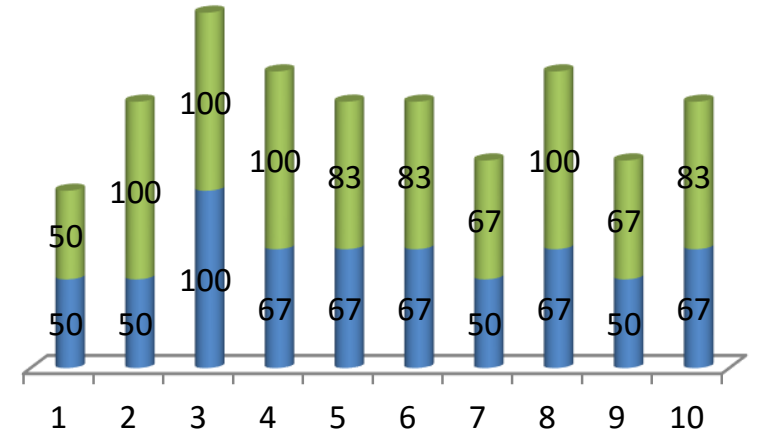

(Fig. 17- Grammar and Vocabulary - Comparison Pre and Post Training)

\section{Accent and Pronunciation}

Post Training Status $\square$ Pre Training Status

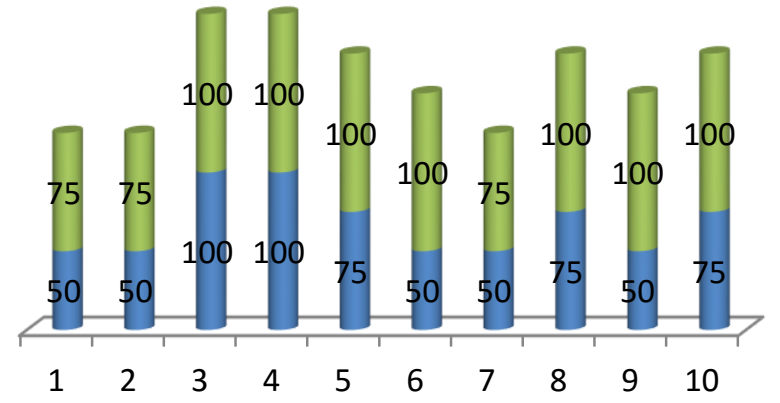

(Fig. 18- Accent and Pronunciation - Comparison Pre and Post Training)

\section{Voice Modulation}

$\square$ Post Training Status $\quad$ Pre Training Status

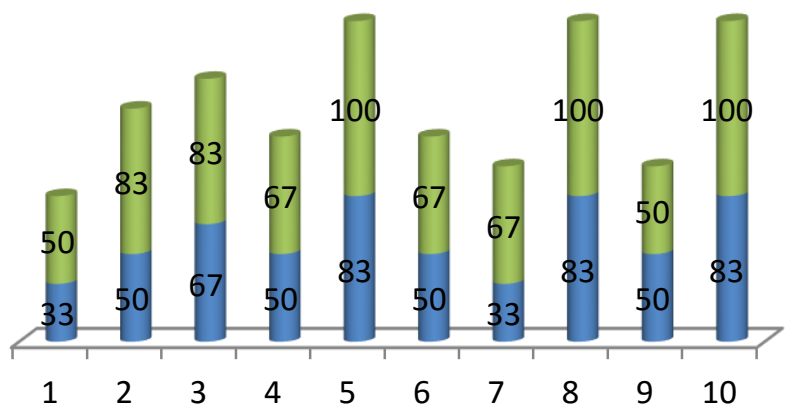

(Fig. 19- Voice Modulation - Comparison Pre and Post Training)

\section{Rate of Speech}

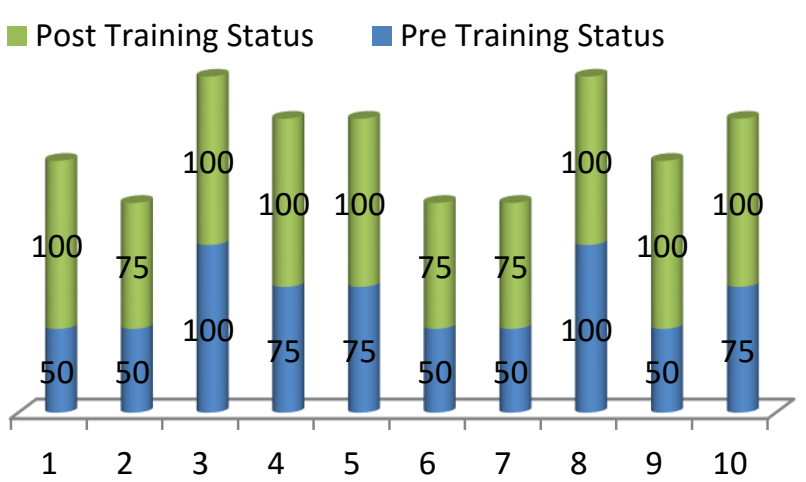

(Fig. 20- Rate of Speech - Comparison Pre and Post Training)

\section{Content}

\section{Opening}

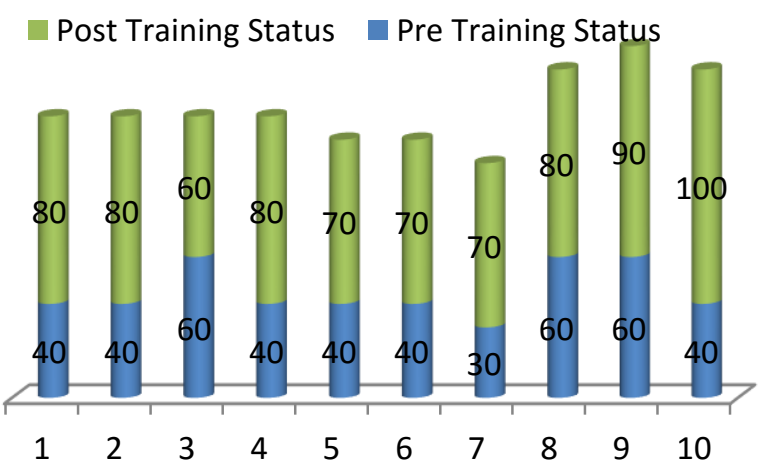

(Fig. 21- Opening - Comparison Pre and Post Training)

\section{Message \\ - Post Training Status Pre Training Status}

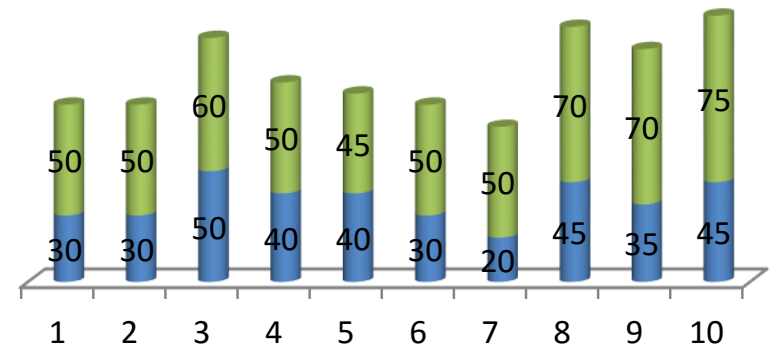

(Fig. 22- Message - Comparison Pre and Post Training) 


\section{Closure}

Post Training Status

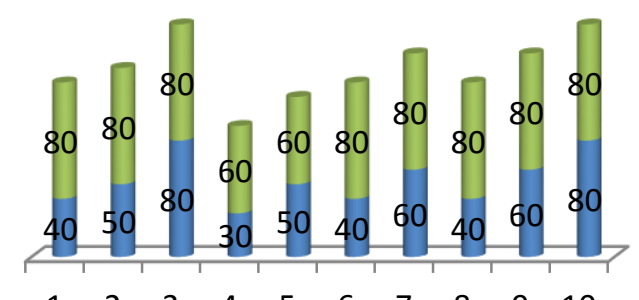

$\begin{array}{llllllllll}1 & 2 & 3 & 4 & 5 & 6 & 7 & 8 & 9 & 10\end{array}$

(Fig. 23- Closure - Comparison Pre and Post Training)

\section{Inferences:}

The inferences drawn out from the experiment are as follows:

1. Students' body language was improved in the form of Eye contact, hand movements, posture, body movements and facial expressions.

2. $40 \%$ students showed improvement in grammar and vocabulary.

3. $70 \%$ showed improvement in the right pronunciation and accent.

4. $30 \%$ students showed improvement in Voice Modulation.

5. $70 \%$ of students showed improvement in the rate of speech.

6. $10 \%$ of the students showed improvement in the opening section of content delivery. The rest of them showed gradual improvement though.

7. Not a single student could reach hundred percent improvements in the Message section. But gradual improvement was seen.

\section{Other Major Changes Observed:}

\section{Confidence :}

The students showed tremendous improvement in the confidence level. The students who were hesitant during their Baseline Evaluation were found to show improvement in the confidence level by the time they reached the Final Term Evaluation.

\section{Time Management:}

Students learnt how to manage time well. They learnt how to share maximum information on the topic in the stipulated time frame and be precise. They acquired this through continuous recording and rehearsals at home before they came into the class for the presentation.

\section{Reading Skills:}

Reading anything apart from the prescribed syllabus is highly impossible for today's students. Exploring a world of reading novels was a new experience for most of the students. Reading novels for imbibing morals and improving language was altogether a new experience for the students.

\section{Redefining ones' limits:}

Students were seen not only competing amongst themselves but competing with themselves. By watching their videos and with the thorough Vis a - Vis interaction with the faculty they started beating themselves and their performances with better performance. It inculcated into them the act of redefining their own limits.

5. Learning from failures:

Students learnt from their failures. They accepted their mistakes with open arms and worked on them to overcome them and showed better performances during the presentation subsequently.

\section{Self Motivation:}

The concept of self motivation was seen eventually growing in the student which in itself was a big change that students reported and shared happily.

\section{Conclusions}

The Vis-a-Vis Evaluation Approach helped students to hone their presentation skills. It also gave them an opportunity to understand the skills better. The most important thing is students read three different novels which also highlighted the importance of reading physical hard bound books.

The major changes that were seen in the students were their improvement in confidence level, time management, reading skills. They also learnt to redefine their limits, learn from failure and self motivation.

The Vis-a-Vis session with each student gave them a platform to discuss their queries related to their performance and marks with the faculty. The students if on continuous basis follow the guidelines imparted and inculcate the habit of planning, writing right script and recording their presentations with rehearsals for sure can become good presenters.

\section{References}

${ }^{1}$ Graham Ballinger (2017) The importance of communication skills in engineers, The Ohio state engineer Magazine, The Ohio state University.

${ }^{2}$ International Journal on Arts, Management and Humanities 1(1): 1-6 (2012) ISSN No. (Online): 2319 5231 Communication Skills for Engineers in Global Arena Shikha Seetha Department of Humanities, VNS Institute of Technology, Bhopal, (MP)

${ }^{3}$ https://wiki.ubc.ca/Presentation_Skills - University of British Columbi)

${ }^{4}$ Cambridge English for Engineering by Mark Ibbotson, Cambridge University Press, 2008. 